\title{
Dendritic cells potently purge latent HIV-1 beyond TCR-stimulation, activating the PI3K-Akt-mTOR pathway
}

\author{
Thijs van Montfort ${ }^{\mathrm{a}, *}$, Renée van der Sluis ${ }^{\mathrm{a}}$, Gilles Darcis ${ }^{\mathrm{a}, \mathrm{b}}$, Doyle Beaty ${ }^{\mathrm{a}}$, Kevin Groen ${ }^{\mathrm{a}}$, \\ Alexander O. Pasternak ${ }^{a}$, Georgios Pollakis ${ }^{c}$, Monique Vink ${ }^{\text {a }}$, Ellen M. Westerhout ${ }^{\mathrm{d}}$, Mohamed Hamdi ${ }^{\mathrm{d}}$, \\ Margreet Bakker a, Boas van der Putten ${ }^{a}$, Suzanne Jurriaans ${ }^{a}$, Jan H. Prins ${ }^{\text {e }}$, Rienk Jeeninga ${ }^{a}$, Adri A.M. Thomas ${ }^{\mathrm{f}}$, \\ Dave Speijer ${ }^{g}$, Ben Berkhout ${ }^{\mathrm{a}}$ \\ a Department of Medical Microbiology, Laboratory of Experimental Virology, Amsterdam University Medical Centers, Amsterdam, Meibergdreef 15, 1105AZ, the Netherlands \\ b Department of Infectious Diseases, Liege University Hospital, Liege, Belgium \\ c Department of Clinical Infection, Microbiology and Immunology (CIMI), University of Liverpool, Liverpool, 8 West Derby Street, United Kingdom \\ d Department of Oncogenomics, Amsterdam University Medical Centers, Amsterdam, Meibergdreef 15, 1105AZ, the Netherlands \\ e Department of Internal Medicine, Amsterdam University Medical Centers, Amsterdam, Meibergdreef 15, 1105AZ, the Netherlands \\ ${ }^{\mathrm{f}}$ Department Developmental Biology, Faculty Beta-Science, Utrecht, Padualaan 8, 3584, CH, the Netherlands \\ g Department of Medical Biochemistry, Amsterdam University Medical Centers, Amsterdam, Meibergdreef 15, 1105AZ, the Netherlands
}

\section{A R T I C L E I N F O}

\section{Article history:}

Received 4 October 2018

Received in revised form 1 February 2019

Accepted 6 February 2019

Available online xxxx

\section{Keywords:}

Dendritic cells

Latency

PI3K

Akt

mTOR

Activated T cells

\begin{abstract}
A B S T R A C T
Background: The latent HIV-1 reservoir in treated patients primarily consists of resting memory $\mathrm{CD}^{+}{ }^{+} \mathrm{T}$ cells. Stimulating the T-cell receptor (TCR), which facilitates transition of resting into effector T cells, is the most effective strategy to purge these latently infected cells. Here we supply evidence that TCR-stimulated effector T cells still frequently harbor latent HIV-1.

Methods: Primary HIV-1 infected cells were used in a latency assay with or without dendritic cells (DCs) and reversion of HIV-1 latency was determined, in the presence or absence of specific pathway inhibitors.

Findings: Renewed TCR-stimulation or subsequent activation with latency reversing agents (LRAs) did not overcome latency. However, interaction of infected effector cells with DCs triggered further activation of latent HIV-1. When compared to TCR-stimulation only, $\mathrm{CD}^{+} \mathrm{T}$ cells from aviremic patients receiving TCR + DC-stimulation reversed latency more frequently. Such a "one-two punch" strategy seems ideal for purging the reservoir. We determined that DC contact activates the PI3K-Akt-mTOR pathway in CD4 ${ }^{+} \mathrm{T}$ cells.

Interpretation: This insight could facilitate the development of a novel class of potent LRAs that purge latent HIV beyond levels reached by T-cell activation.
\end{abstract}

(C) 2019 Published by Elsevier B.V. This is an open access article under the CC BY-NC-ND license (http:// creativecommons.org/licenses/by-nc-nd/4.0/).

\section{Introduction}

Early on in HIV infection, cellular reservoirs containing latent HIV-1 are formed [1]. These cells contain a stably integrated and complete viral genome, but do not express sufficient amounts of viral proteins to drive virus production and to be recognized by the immune system. Resting memory $\mathrm{CD}^{+} \mathrm{T}$ cells are the main cell type harboring latent HIV-1 in patients after prolonged therapy [2,3], but T cells with shorter halflives, such as effector T cells, can also harbor latent HIV-1 [4,5]. Latency is established and maintained through multiple mechanisms that act at transcriptional and post-transcriptional levels [6]. At the transcriptional level, accessibility of the HIV-1 LTR promoter could be blocked in

\footnotetext{
* Corresponding author.

E-mail address: T.vanmontfort@amc.uva.nl (T. van Montfort).
}

repressive chromatin structures (which can be overcome with histone deacetylase (HDAC) inhibitors) or by the sequestration of transcription initiation factors such as NF-кB/NFAT/AP-1. Other blocks to HIV-1 transcription include inefficient elongation due to the lack of elongation factors such as P-TEFb or the presence of negative elongation factors (NELFs). These elongation factors influence the RNA polymerase complex and determine whether transcription is prematurely aborted after synthesis of the trans-activation response (TAR) region or extended towards the formation of full-length HIV-1 RNA transcripts. Yukl et al. recently described that HIV latency at the transcriptional level occurs mainly due to inefficient RNA elongation accompanied by a lack of splicing and polyadenylation factors rather than the absence of transcription initiation factors [7]. Inefficient export of viral RNA from the nucleus may also contribute to HIV-1 latency, either due to low levels of Rev protein [8,9] or cellular co-factors like Matrin-3 or PTB that assist in nuclear RNA export [10,11]. 


\section{Research in context}

\section{Evidence before this study}

Management of HIV has significantly improved over the past decades, due to combinations of antiretroviral drugs preventing viral replication. However, the virus cannot be eradicated because of the so-called latent reservoir, primarily consisting of resting memory $\mathrm{CD}^{+}{ }^{+} \mathrm{T}$ cells. Several strategies to target this reservoir have been tested, but none are satisfactory. Stimulating the Tcell receptor (TCR), facilitating transition of resting into effector $T$ cells, is currently the most effective strategy to purge these latently infected cells.

\section{Added value of this study}

Here we demonstrated that TCR-stimulated effector T cells can still contain latent HIV-1. Renewed TCR-stimulation or activation of such effector cells with latency reversing agents (LRAs) did not overcome latency. We decided to concentrate on alternative methods of activation next. We found that the interaction of infected effector cells with dendritic cells (DCs) could further activate latent HIV-1. Using such a "one-two punch" strategy might thus be ideal for purging the bodily latent reservoir. Indeed, $\mathrm{CD}^{+}{ }^{+} \mathrm{T}$ cells taken from aviremic patients, which received our DC-stimulation on top of TCR-stimulation, more frequently reversed latency. Our experiments also showed that latency reversal upon DC contact is due to the activation of the PI3K-AktmTOR pathway in the target $\mathrm{CD} 4^{+} \mathrm{T}$ cells.

\section{Implications of all the available evidence}

These findings might aid the development of novel classes of potent LRAs as drugs used to purge latent HIV beyond the current levels reached by T-cell activation.

One of the proposed strategies to exhaust the reservoir is a "shock and kill" treatment in which latency-reversing agents (LRAs) purge HIV-1 from latency, while uninfected cells are protected against virus infection with antiretroviral therapy. Virus-induced cell death or cytotoxic T-cell killing of virus-producing cells was proposed to eliminate the reactivated cells. Stimulation of the T-cell receptor (TCR) to induce the transition of resting into effector T cells is currently the most effective strategy to purge latent HIV. Ex vivo stimulation of the TCR with PHA or CD3-CD28 antibodies can purge approximately 1 cell per million resting memory T cells ( $=1 \mathrm{IUPM}$ ), as determined with the gold standard quantitative viral outgrowth assay (qVOA) [12]. Based on fullgenome sequencing, however, it has been estimated that the intact HIV-1 reservoir size is around 30 cells per million resting T cells in treated patients [12]. This implies that T-cell activation can only purge a fraction of the HIV reservoir and that additional stimuli are required to purge larger portions of latently infected cells. We previously developed an HIV-1 latency assay for activated effector T cells as opposed to quiescent resting T cells [5]. Stimulation of these effector T cells with DCs purged HIV-1 latency efficiently ( 3-fold), whereas stimulation with other LRAs had no impact on latency reversal. This in vitro HIV-1 latency model shows that many HIV-1 infected T cells, although fully activated, keep their latent state. This finding is corroborated with data from an ex vivo study [13], using TCR stimulation of quiescent resting patient $\mathrm{T}$ cells. Although the T cells were fully activated, a second or third TCR-stimulation could further increase latency reversal 2-3 fold, implying that more is needed to purge activated latently infected cells. resting $T$ cells
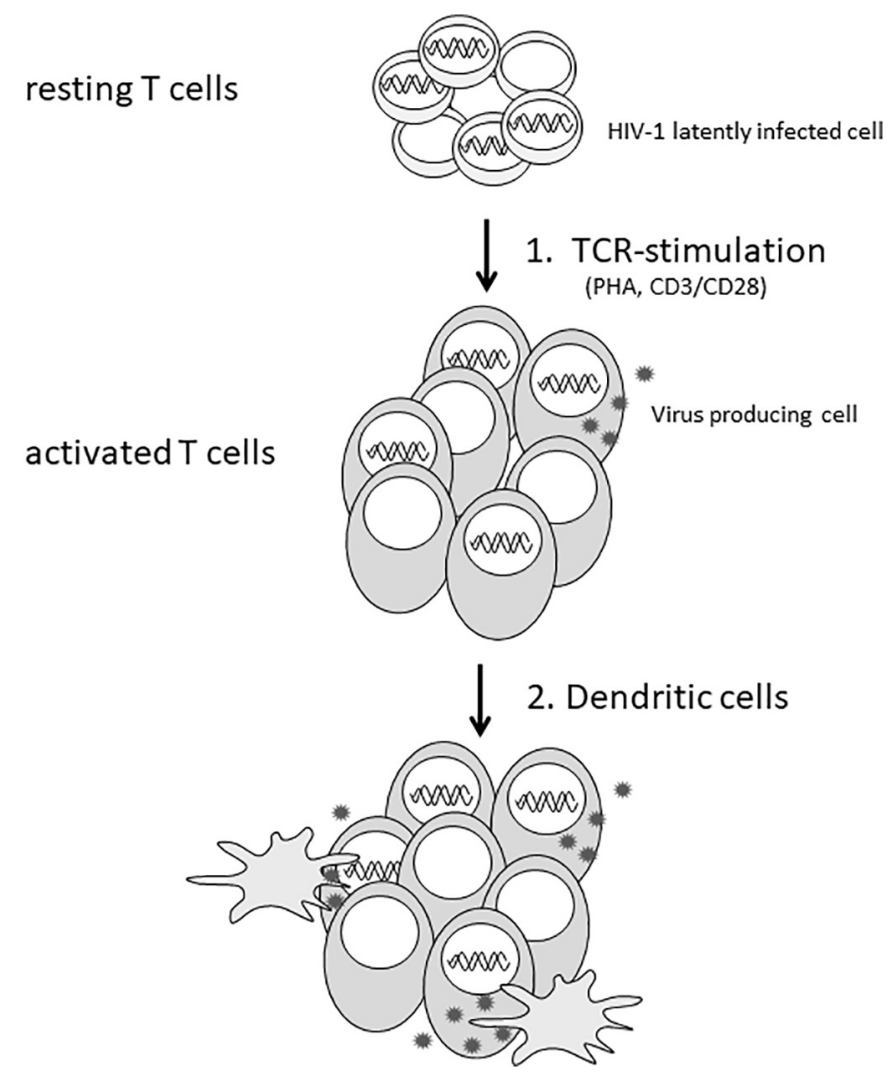

Fig. 1. Purging latent HIV-1 according to the "one-two punch" strategy. First, resting T cells are activated by stimulating the $\mathrm{T}$ cell receptor. Activated effector T cells are subsequently brought into contact with DCs to increase the purging efficiency of latent HIV-1.

Here we want to stress the difference between latent HIV-1 infection reversal and cell activation and the fact that current strategies towards human treatment rely on shifting resting T cells to activated phenotypes. Cell activation however, is relatively inefficient in also activating latent HIV-1 expression. Our observations offer insights to guide new approaches to increasing the efficiency of latent HIV-1 reversion. We show that the PI3K-Akt-mTOR pathway has to be triggered to activate

Table 1

HIV-1 patient history.

\begin{tabular}{llllll}
\hline Patient & $\begin{array}{l}\text { Age } \\
\text { (years) }\end{array}$ & $\begin{array}{l}\text { Load } \\
\text { copies/ml }\end{array}$ & Current treatment & CD4 & $\begin{array}{l}\text { Duration } \\
\text { UVL (years) }\end{array}$ \\
\hline 1 & 37 & $<40$ & TDF/FTC/EFV & ND & 4.2 \\
2 & 81 & $<40$ & TDF/FTC/EFV & 0.46 & 5.2 \\
3 & 48 & $<40$ & DTG/3TC/ABC & 0.38 & 2.4 \\
4 & 48 & $<40$ & EVG/c/ TAF/FTC & ND & 1.2 \\
5 & 54 & $<40$ & NVP/TDF/FTC & ND & 12.9 \\
6 & 42 & $<40$ & EVG/C/TAF/FTC & 0.90 & 3.9 \\
7 & 23 & $<40$ & EFV/3TC/ABC & ND & $\geq 4$ \\
8 & 50 & $<40$ & DTG/3TC/ABC & 0.80 & 5.9 \\
9 & 56 & $<40$ & LPV/r/TDF/FTC & ND & 12.7 \\
10 & 52 & $<40$ & NVP/3TC/ABC & 0.49 & 13,2 \\
11 & 61 & $<40$ & RAL/DRV/r/TDF/FTC & 0.38 & 8,6 \\
12 & 50 & $<40$ & EVG/c/ TDF/FTC & ND & 12,9 \\
13 & 55 & $<40$ & TDF/FTC/EFV & 0.73 & 2,3 \\
14 & 69 & $<40$ & NVP/TDF/FTC & ND & 11,5 \\
15 & 24 & $<40$ & ATZ/r/3TC/ABC & ND & $\geq 1$ \\
16 & 41 & $<40$ & NVP/TDF/FTC & 0.92 & 13,1 \\
35 & 48 & $<40$ & S/r/TDF/FTC & ND & $\leq 14.2$ \\
36 & 62 & $<40$ & NVP/TDF/FTC & ND & $\leq 9.9$ \\
37 & 51 & $<40$ & DRV/r/RAL & 520 & $\geq 1.6$ \\
\hline
\end{tabular}

ND $=$ Not determined.

TDF: tenofovir disoproxil fumarate; FTC: emtricitabine; EFV: efavirenz; DTG: dolutegravir; 3TC: lamivudine; ABC: abacavir; EVG/c: elvitegravir cobicistat; TAF: tenofovir alafenamide; NVP: Nevirapine; LPV: lopinavir; r: ritonavir; RAL: raltegravir; DRV: darunavir; ATZ: atazanavir ritonavir; s: Saquinavir. 
A

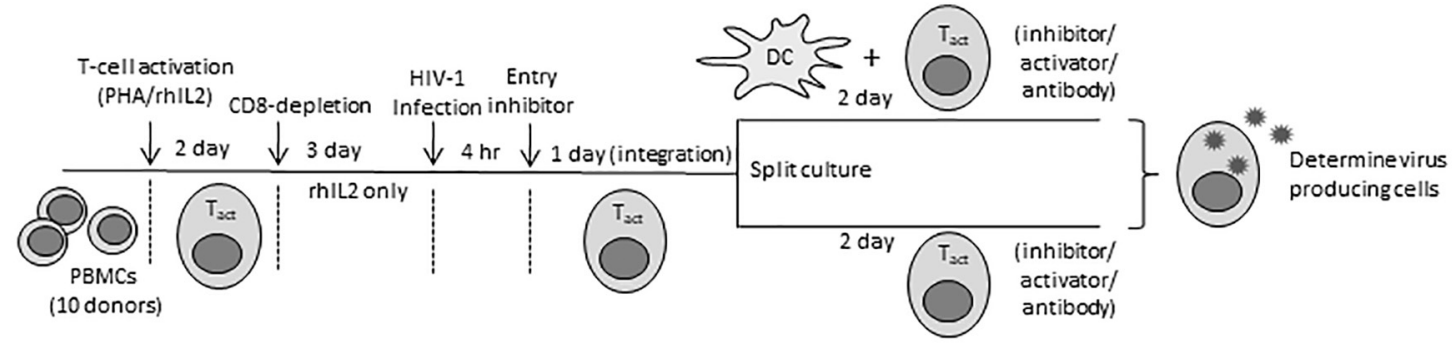

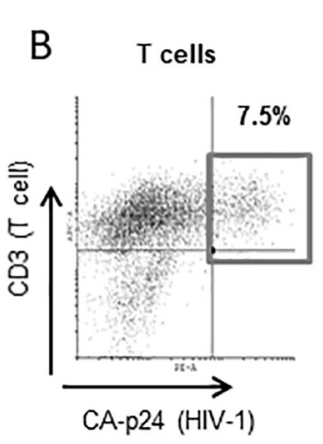

T cells +

Dendritic cells

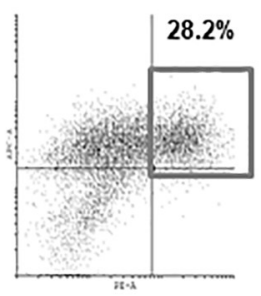

C
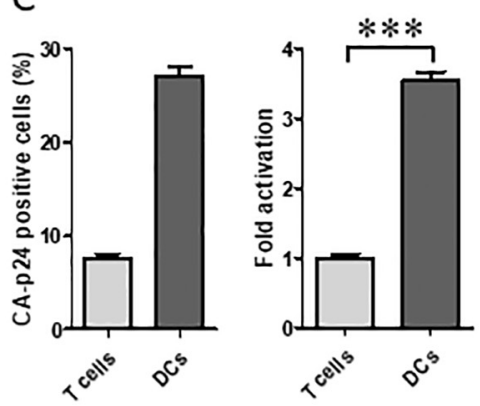

D

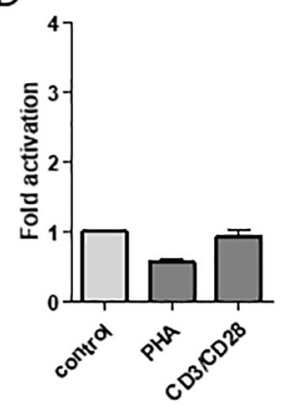

E

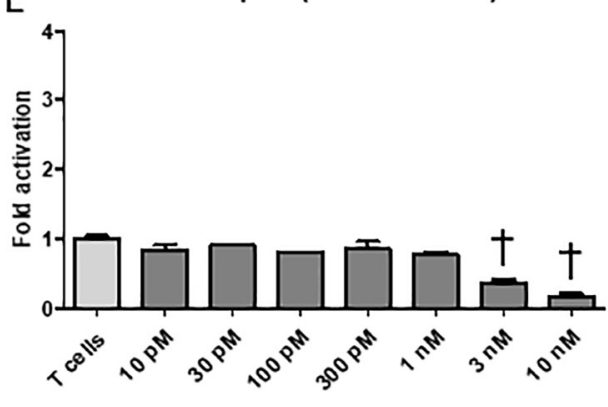

$\mathrm{F}$

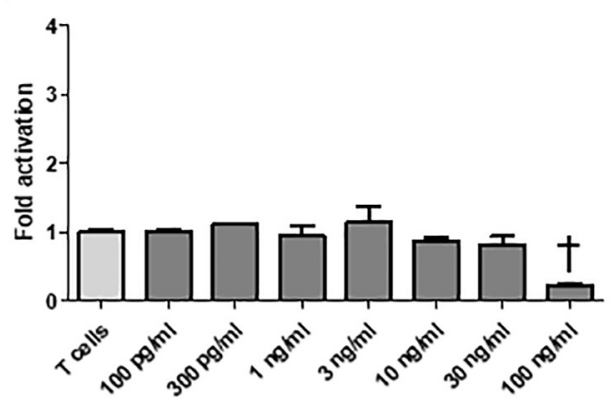

G

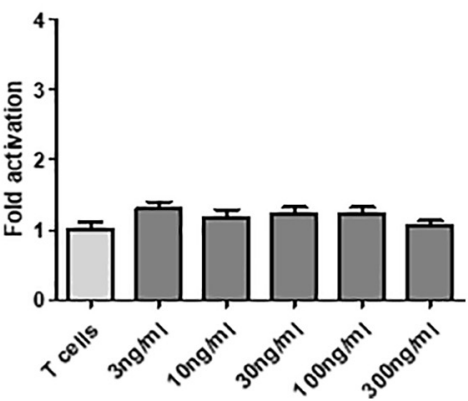

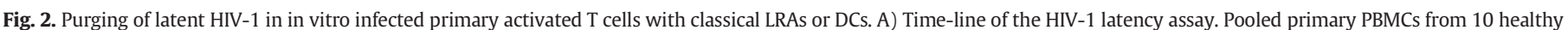

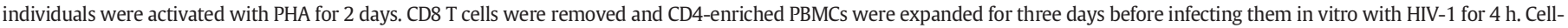

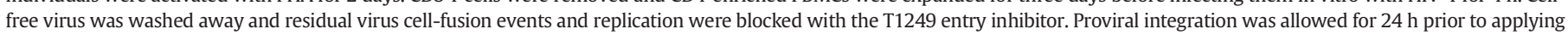

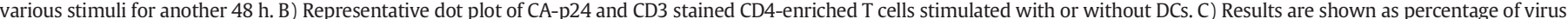

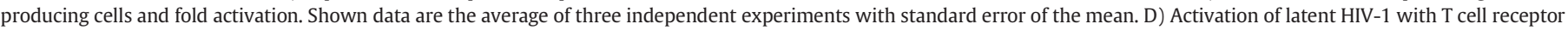

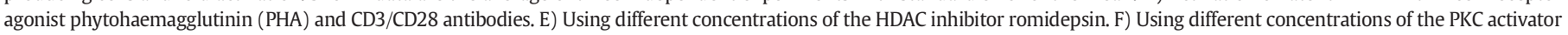
prostratin or TNF $\alpha(G)$. Representative data are shown with standard error of the mean of at least three independent experiments. Drug toxicity is indicated with $\varsigma^{\circ}$.

virus production in PHA pre-activated T cells, which is achieved upon DC contact. Importantly, we show that reversal of HIV-1 latency in T cells isolated from treated aviremic patients (See Table 1), even when activated with PHA, is further stimulated by DCs. DC coculture increases the frequency of HIV-1 release (all 9 patients) compared to PHA alone (4 out of 9). Using an adapted quantitative virological outgrowth assay ( $q \mathrm{VOA}$ ), the golden standard to measure reversal of HIV-1 latency, we found replicating virus in 8 out of 12 patients (starting at a baseline of 2 out of 12 patients upon PHA stimulation only) upon DC treatment. Collectively, this "one-two punch" strategy (PHA + DCs) can purge the reservoir more potently than PHA treatment alone (Fig. 1). These findings could direct the development of novel LRA treatments that also strongly stimulate the PI3K-Akt-mTOR pathway. The new insights could also be used for the design of a new sensitive culture-based assay to measure the intact HIV-1 reservoir.

\section{Material and methods}

\subsection{Reagents}

The fusion inhibitor T1249 was obtained from Pepscan (Therapeutics BV, Lelystad, The Netherlands) and used at a final concentration of
$100 \mathrm{ng} / \mathrm{ml}$. Antibodies against CD9, CD63, CD81, CD83, CD86, CD151, CD45RO, CD45RA, were purchased from Biolegend (San Diego, CA, USA). Other antibodies are directed against CA-p24 (clone KC-57RD1) (Beckman Coulter, Brea, CA, USA) and CD3-APC (BD Pharmingen, Breda, the Netherlands).

\subsection{Cells}

Human peripheral blood mononuclear cells (PBMCs) were isolated from buffy coats (Central Laboratory Blood Bank, Amsterdam, The Netherlands) by use of a Ficoll gradient and frozen in multiple vials. When required, PBMCs were thawed, activated with phytohaemagglutinin (PHA, Remel, $2 \mu \mathrm{g} / \mathrm{ml}$ ) and cultured in RPMI medium supplemented with 10\% FCS and recombinant human IL-2 (rhIL-2, Novartis, $100 \mathrm{U} / \mathrm{ml}$ ). On day 2 of culture, $\mathrm{CD}^{+}{ }^{+} \mathrm{T}$ lymphocytes were depleted using CD8 immunomagnetic beads (Dynal, Invitrogen, Carlsbad, $\mathrm{CA}$, USA) and the CD4 ${ }^{+}$-enriched $\mathrm{T}$ lymphocytes were cultured for 3 more days before use in the in vitro latency assay.

Monocytes were isolated from PBMCs with CD14 magnetic beads from Miltenyi Biotec ( $\mathrm{GmbH}$, Bergisch Gladbach, Germany) according to the manufacturer's protocol. Purified monocytes were cultured in RPMI 1640 medium containing 10\% FCS and differentiated into 
monocyte-derived DCs by stimulation with $45 \mathrm{ng} / \mathrm{ml}$ interleukin- 4 (rIL4; Biosource, Nivelles, Belgium) and $500 \mathrm{U} / \mathrm{ml}$ granulocyte macrophage colony-stimulating factor (GM-CSF; Schering-Plough, Brussels, Belgium) on day 0 and 2, and used on day 6 [14].

HEK 293 T cells were grown as a monolayer in Dulbecco's minimal essential medium (Gibco, BRL, Gaithersburg, MD) supplemented with $10 \%(\mathrm{v} / \mathrm{v}$ ) fetal calf serum (FCS), $40 \mathrm{U} / \mathrm{ml}$ penicillin, $40 \mu \mathrm{g} / \mathrm{ml}$ streptomycin at $37{ }^{\circ} \mathrm{C}$ and $5 \% \mathrm{CO}_{2}$.

SupT1 CCR5 expressing T cells, a kind gift of prof. J. Hoxie [15] were cultured in RPMI 1640 medium containing 10\% FCS.

\subsection{Virus}

Plasmid DNA encoding the CXCR4-using HIV-1 LAI primary isolate was transiently transfected in HEK293T cells with the lipofectamin 2000 reagent according to manufacturer's protocol (Fisher Scientific, Landsmeer, NL). Virus supernatant was harvested 2 days after transfection, passed through a $0.2 \mu \mathrm{m}$ filter and stored in aliquots at $-80^{\circ} \mathrm{C}$. The concentration of the virus stocks was determined by CA-p24 ELISA.

\subsection{In vitro HIV-1 latency assay}

HIV-1 infected cells were used in the latency assay as described previously $[16,19,20]$. In short, PHA-activated $\mathrm{CD}^{+} \mathrm{T}$ lymphocytes $(1.5$ $\times 10^{6}$ or $2.0 \times 10^{6}$ cells) were infected with HIV- 1 for 4 h (20 ng CAp24). To establish infection over a $4 \mathrm{~h}$ window, excess virus was diluted with three washes and cells were incubated with $100 \mathrm{ng} / \mathrm{ml}$ T1249 fusion inhibitor to prevent late fusion events and new rounds of virus replication. Cells were incubated for 24 h to allow HIV-1 proviral
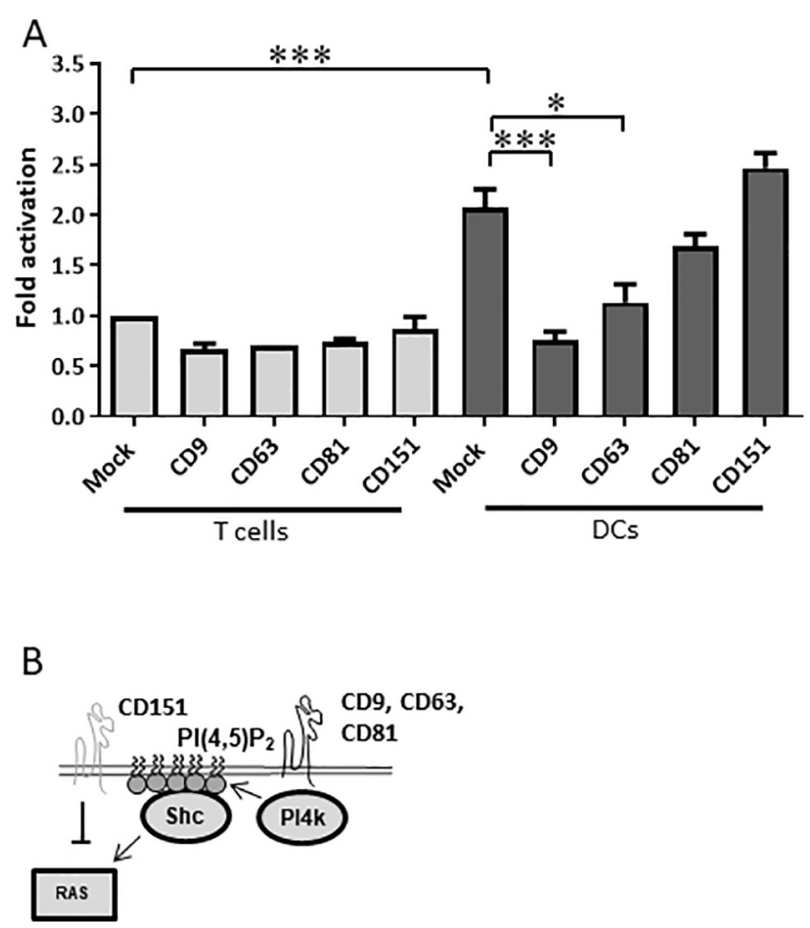

Fig. 3. Reversion of latency depends on specific tetraspanin enriched microdomains formed between DCs and T cells. A) Fold activation from latency of infected primary T cells cultured with or without DCs in the presence of $20 \mu \mathrm{g} / \mathrm{ml} \mathrm{CD9}, \mathrm{CD} 63, \mathrm{CD} 81$ and CD151 antibodies targeting specific tetraspanin enriched microdomains (TEMs). B) Schematic overview, adapted from Hemler et al. [22], regarding the role of the tetraspanins targeted in activating the RAS signaling cascade. Phosphatidylinositol 4kinase is recruited to the membrane in CD9, CD63, CD81 TEMs and phosphoinositides, such as phosphatidylinositol-4,5- bisphosphate $\left(\mathrm{PI}(4,5) \mathrm{P}_{2}\right)$ are produced. This causes activation of Shc, resulting in the activation of the RAS signaling pathway. CD151 negatively influences the RAS activation pathway [22]. Representative data are plotted as the average fold activation with standard error of the mean of at least three independent experiments. integration. Subsequently, cells were treated with or without DCs (ratio DC:T 1:3), with or without $20 \mu \mathrm{g} / \mathrm{ml} \mathrm{CD9/CD63/CD81/CD151} \mathrm{an-}$ tibody, or in the presence or absence of drugs for $48 \mathrm{~h}$ in the continued presence of T1249. Single cells were analysed for the presence of the CD3 $\mathrm{T}$ cell receptor and expression of intracellular CA-p24 by flow cytometry $[5,16]$. The percentage of CA-p24 positive CD3-positive cells in the treated culture was divided by the percentage of CA-p24 cells in the mock treated culture and reported as fold activation (a measure of HIV-1 latency reversion).

\subsection{Intracellular CA-p24 analysis}

Cells were fixed in $4 \%$ formaldehyde at room temperature for $20 \mathrm{~min}$ and subsequently washed with $2 \%$ FACS buffer (PBS supplemented with $2 \%$ FCS). The cells were permeabilised with BD Perm/Wash ${ }^{\mathrm{TM}}$ buffer (BD Pharmingen) and antibody staining was performed in BD Perm/Wash ${ }^{\mathrm{TM}}$ at room temperature for $1 \mathrm{~h}$. HIV-1 was intracellularly stained with an CA-p24 antibody and T lymphocytes were discriminated from DCs using the $\mathrm{T}$ cell receptor $\mathrm{CD} 3$ antibody. Unbound antibody was removed and the cells were analysed on a BD Canto II flow cytometer with BD FACSDiva Software v6.1.2 (BD biosciences, San Jose, CA) in FACS buffer. The T lymphocyte population was defined based on forward/sideward scatter and CD3 expression. Virus production on the gated $\mathrm{T}$ lymphocyte population was determined by measuring the intracellular viral CA-p24 protein level. Dendritic cells and $\mathrm{T}$ cell doublets were removed from the analyses by gating.

\subsection{Human phospho kinase array}

PHA-activated $\mathrm{CD}^{+}{ }^{+} \mathrm{T}$ lymphocytes were infected according to the in vitro HIV-1 latency assay protocol. Infected PBMCs $\left(15 \times 10^{6}\right)$ were incubated with $7 \times 10^{6} \mathrm{DCs}$ or without DCs for $2.5 \mathrm{~h}$. To disrupt the DC-T cell interaction, which was observed after $1 \mathrm{~h}$ incubation, cell cultures were resuspended and washed twice in cold PBS supplemented with 2 mM EDTA and $0.5 \%$ FCS. $\mathrm{CD}^{+}{ }^{+}$T lymphocytes were isolated at $4{ }^{\circ} \mathrm{C}$ using the human $\mathrm{CD} 4{ }^{+} \mathrm{T}$ lymphocytes isolation kit from Miltenyi Biotec according to the manufacturer's protocol. Approximately 10 $\times 10^{6} \mathrm{CD}^{+} \mathrm{T}$ lymphocytes were obtained after the isolation protocol. Cells were pelleted and treated according to the manufacturer's protocol from the human phospho-kinase antibody array kit (R\&D systems).

\subsection{Ethical approval}

Informed written consent was obtained from all participants of this study, and the study was approved by the Medical Ethical Committee of the Academic Medical Center, Amsterdam. All procedures followed were in accordance with the ethical standards of the responsible committee on human experimentation (institutional and national) and with the Helsinki Declaration of 1975, as revised in 2000.

\subsection{Quantification of HIV-1 release into culture supernatant}

Patient-derived $\mathrm{CD} 4^{+} \mathrm{T}$ cells were isolated using the human $\mathrm{CD} 4^{+} \mathrm{T}$ lymphocyte isolation kit (Miltenyi Biotec) according to the manufacturer's protocol. Between 1.4 and $2.0 \times 10^{6}$ cells were used per condition and treated with $2 \mu \mathrm{g} / \mathrm{ml}$ PHA, heterologous monocyte-derived DCs in a 1:3 ratio (DC:T), PHA combined with DCs (1:3 ratio) or left untreated for $72 \mathrm{~h}$ in RPMI1640 medium containing rhIL-2 and $80 \mathrm{ng} / \mathrm{ml}$ saquinavir. Cell-free supernatant was collected by centrifugation for $5 \mathrm{~min}$ at 500 rcf. Extracellular HIV-1 RNA was isolated from $300 \mu$ of the supernatant using the Boom isolation method [17] with the addition of $2 \mu \mathrm{g}$ of carrier RNA (poly A RNA, Qiagen, Venlo, The Netherlands) and processed for reverse transcription and first PCR using QIAGEN $®$ OneStep RT-PCR kit (Qiagen, Venlo, The Netherlands) according to the manufacturer's instructions. The primers used were TAR-F (5'-GGGTCTCTCTG GTTAGACCAG-3') and HIV-FOR [18]. The PCR settings were as follows: 

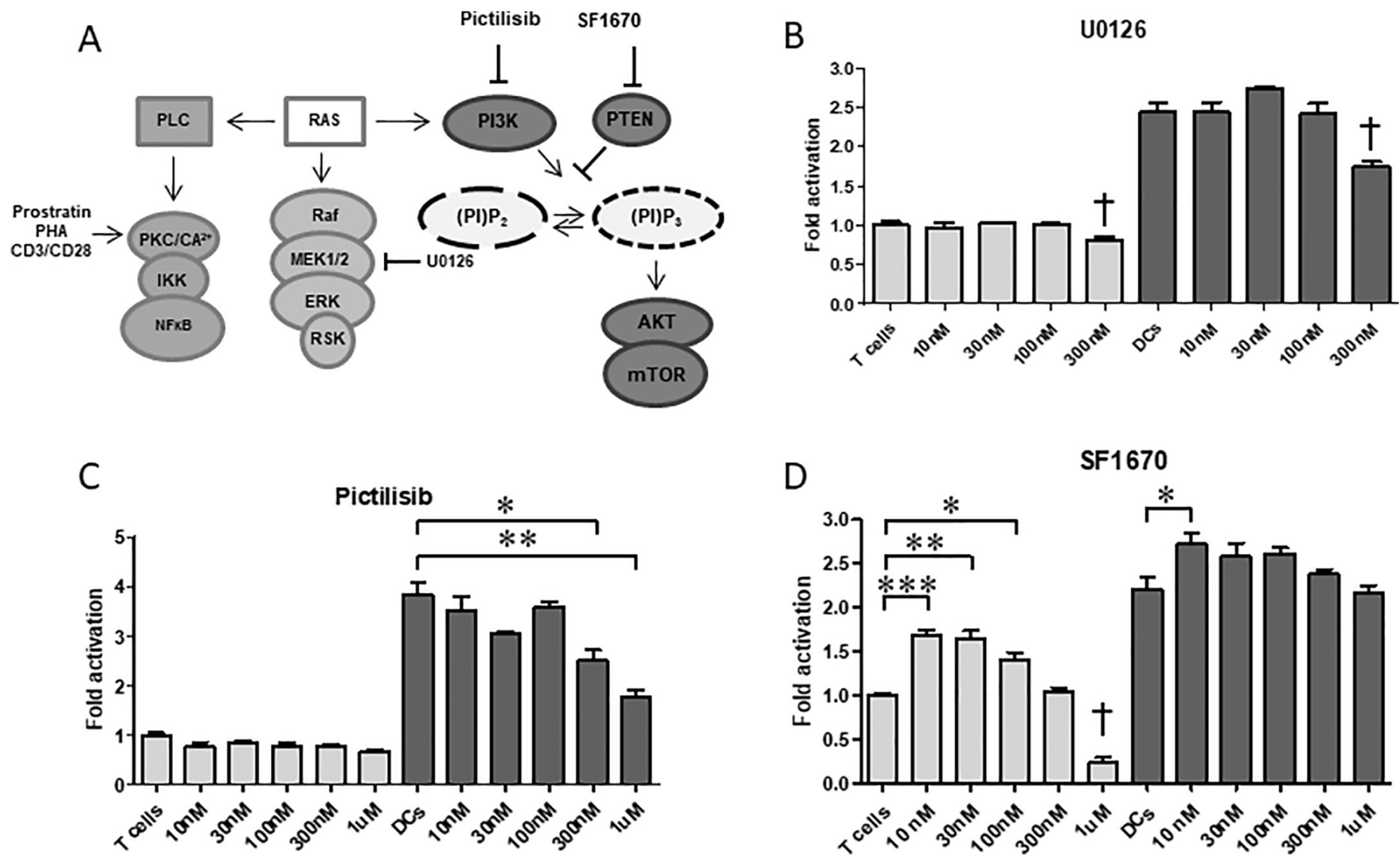

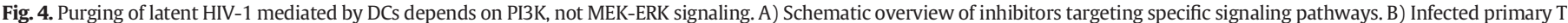

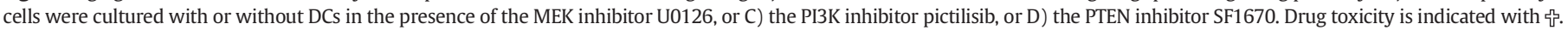

$94^{\circ} \mathrm{C}$ for 3 min, followed by 15 cycles of $94^{\circ} \mathrm{C}$ for $30 \mathrm{~s}, 55^{\circ} \mathrm{C}$ for $30 \mathrm{~s}$, and $72{ }^{\circ} \mathrm{C}$ for $1 \mathrm{~min}$, followed by $72{ }^{\circ} \mathrm{C}$ for $10 \mathrm{~min}$. Two $\mu$ of the first PCR product were subsequently used as a template in the second, seminested, real-time, PCR amplification, performed using the primers and a TaqMan probe described by Malnati et al. [18].

\section{9. qVOA with 1) PHA, 2) DC one-two punch}

Isolated $\mathrm{CD} 4^{+} \mathrm{T}$ cells from aviremic patients were activated with 2 $\mu \mathrm{g} / \mathrm{ml}$ PHA for $72 \mathrm{~h}$ in RPMI1640 medium containing rhIL-2 and $100 \mathrm{ng} / \mathrm{ml}$ entry inhibitor T1249. Cells were washed three times and cultured in 96-well plate with a cell density of $2.0 \times 10^{5} \mathrm{CD} 4 \mathrm{~T}$ cells/ well with or without $8.3 \times 10^{4}$ DCs (1:3 DC:T cell ratio) in fresh RPMI1640 containing rhIL-2. HIV-1 susceptible SupT1 CCR5 cells (5.0 $\times 10^{4}$ ) were added to the microcultures to disseminate and sustain HIV-1 replication [19]. After 7, 14 and 21 days of culturing half of the culture was used to determine HIV-1 CA-p24 by ELISA [5] and fresh RPMI 1640 media containing $5.0 \times 10^{4}$ SupT1 CCR5 cells was added to sustain $\mathrm{T}$ cell growth and virus replication. The number of infectious units per million (IUPM) cells was determined on the number of HIV1 CA-p24 positive microcultures on day 21 for each condition per million patient-derived CD4 T cells.

\subsection{Statistical analysis}

Significance of differences between groups or pairs was determined by one-way ANOVA and Student's $t$-tests. For patient-derived samples, Fisher's exact tests were used to compare the detectability of HIV-1 extracellular RNA between different conditions. Significance levels: *: $p<.05$; $^{* *}: p<.01 ;{ }^{* * *}: p<.001$. All tests were two-sided and were performed using GraphPad Prism, version 7.

\section{Results}

\subsection{Dendritic cells purge residual latent HIV-1 from PHA-activated T cells}

To investigate the effectiveness of DCs or LRAs in reversing latency in effector T cells, we designed an innovative primary T-cell model. Resting $\mathrm{T}$ cells from healthy donors were activated with PHA for 2 days. $\mathrm{CD}^{+} \mathrm{T}$ cells were removed and $\mathrm{CD} 4^{+} \mathrm{T}$ cells were cultured for three days before infection for $4 \mathrm{~h}$ with HIV-1. New rounds of infection and virus replication were then blocked by addition of the T1249 entry inhibitor. Cells were maintained in culture for $24 \mathrm{~h}$ to allow completion of reverse transcription and DNA integration was allowed to proceed for $24 \mathrm{~h}$. Subsequently, the infected $\mathrm{CD} 4^{+} \mathrm{T}$ cells were co-cultured for $48 \mathrm{~h}$ with or without DCs and in the presence or absence of LRAs (Fig. 2A). As shown before, the percentage of virus-producing $\mathrm{T}$ cells increased from $7.5 \%$ to $28.2 \%$ by DC co-culturing (Fig. 2B). Reversion of latency, expressed as "fold activation" by calculating the percentages of CAp24 positive DC-treated T cells divided by control untreated T cells from three independent infections, was $\sim 3.5$-fold (Fig. 2C). Importantly, this means that for each virus-producing effector T cell, 2 to 3 additional HIV-infected cells could be purged from latency by DCs. Thus, a bigger part of the reservoir could be purged using DCs as an extra stimulation. The observed rate of reversion of HIV-1 latency by DCs is not due to increased viral transmission or integration as extending the period before addition of DCs or use of the integrase inhibitor raltegravir did not change the fold activation. Moreover, the infected activated effector T cells showed heightened expression levels of CD25, CD69, CD45RO and CCR7 and the additional DC stimulation did not change expression levels [5].

Successive stimulation of the T-cell receptor (TCR) has been shown to increasingly revert the level/efficiency of HIV latency in activated T 
cells [13]. The heterologous DCs used in this latency assay might also have non-specifically stimulated the TCR. Re-stimulating the TCR again with phytohaemaglutinin (PHA) or CD3/CD28 antibodies, however, did not purge latency, demonstrating that DC-purging is not triggered via the TCR (Fig. 2D). Other LRAs such as the HDAC inhibitor romidepsin (Fig. 2E), the PKC activator prostratin (Fig. 2F), and the inflammatory cytokine TNF $\alpha$ (Fig. 2G) were also unable to revert additional latent HIV-1, illustrating that reversion of HIV-1 triggered by DCs is different from the LRAs tested and does not depend on T cell receptor activation.

3.2. Tetraspanins are involved in DC-triggered HIV-1 activation in PHAactivated $T$ cells

DCs interact with T cells via immunological synapses where antigen is presented for TCR recognition. Tetraspanins CD9, CD63, CD81, and CD151 play an important role in this process by stabilizing recruited protein complexes in tetraspanin-enriched microdomains (TEMs) [20,21]. To investigate whether the tetraspanins are involved in DCmediated HIV-1 latency reversal in T cells, tetraspanin-specific antibodies $(\mathrm{Ab})$ were added. Blocking of CD9 abrogated HIV-1 latency reversal in effector T cells by DCs, beyond mock-incubated T cell levels. CD9 also showed a negative effect on activation in T cells in the absence of DCs (Fig. 3A), implying that latency is induced. CD63 also blocked DCmediated reversal of latency and modestly induced latency in non-DC treated T cells. A reduction of $\sim 38 \%$ in DC-mediated purging was observed when a CD81 Ab was used while the CD151 Ab had no effect on DC-purging (Fig. 3A). These data suggest that the RAS signaling pathway is targeted by DCs, because the three responsive tetraspanins (CD9, CD63 and CD81) activate this pathway, whereas the non-responsive CD151 tetraspanin inhibits it (Fig. 3B, model adapted from Hemler et al. [22].

\subsection{DC-mediated HIV-1 latency reversal depends on the PI3K-Akt-mTOR pathway}

Active GTP-bound RAS can activate the extracellular signalregulated kinase (Raf-MEK/ERK), phosphoinositide kinase 3 (PI3KAkt-mTOR) and the phospholipase C (PLC)/PKC pathway (Fig. 4A). As shown above, stimulation of the TCR or the PKC pathway with prostratin did not purge latent HIV-1 in effector T cells, illustrating that the PLC-PKC pathway is not involved in DC-purging (Fig. 2D and F). Inhibiting the Raf-MEK/ERK pathway with increasing concentrations of the MEK1/2 inhibitor U0126 (up to $100 \mathrm{nM}$ ) also did not block HIV-1 purging (Fig. 4B) and cell death was observed at $300 \mathrm{nM}$. In contrast, inhibition of the PI3K route with $100 \mathrm{nM}$ pictilisib (GDC-0941) potently inhibited DC purging (Fig. 4C).

To confirm the involvement of the PI3K pathway, we indirectly activated this pathway by inhibiting PTEN with SF1670 (Fig. 4A and D). In accordance with the suggested role of the PI3K-Akt-mTOR pathway in latency reversal, inhibition of PTEN in the T-cell culture reversed HIV-1 latency by $1.7-$ fold. In contrast, inhibition of PTEN increased the DC-purging activity only minimally (and only at high concentrations of SF1670), suggesting that the PI3K-Akt pathway was already active.
A

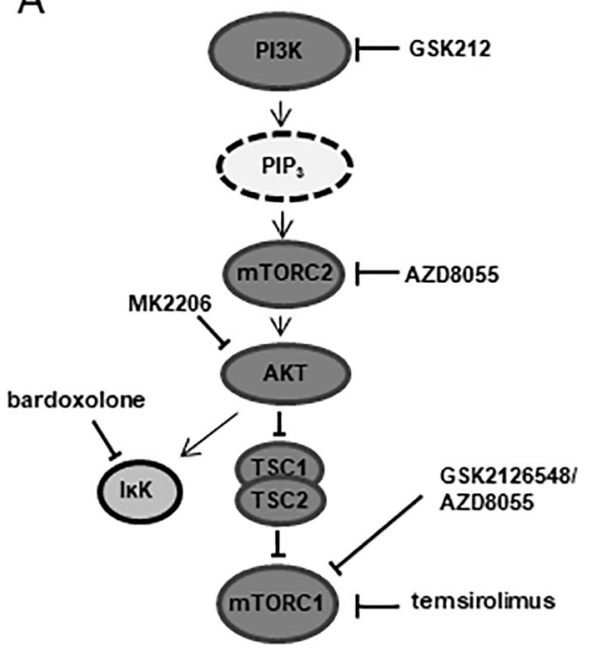

B
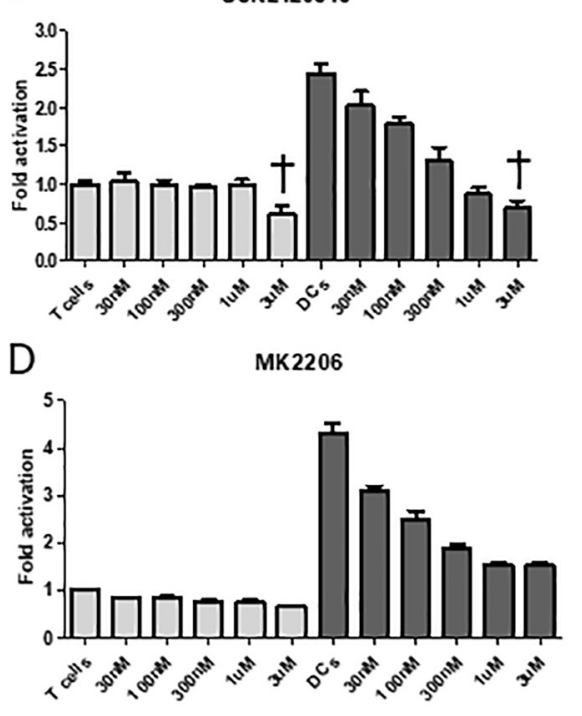

$\mathrm{F}$

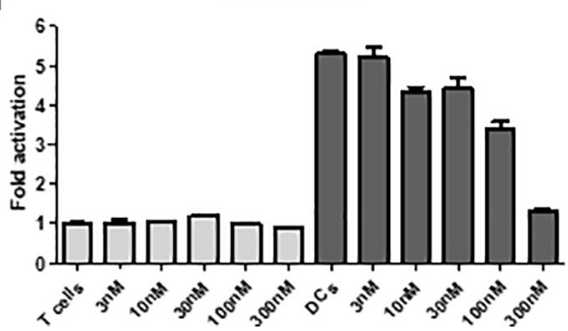

C AZD8055
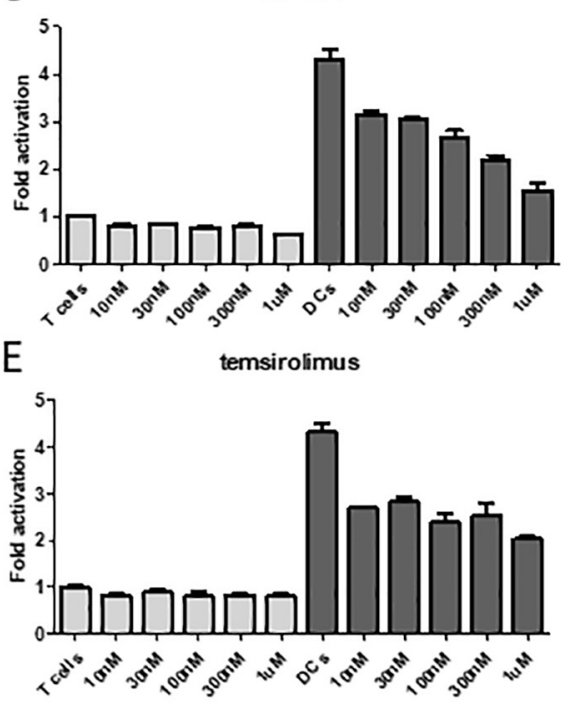

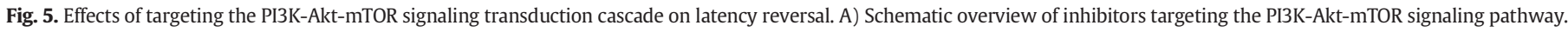

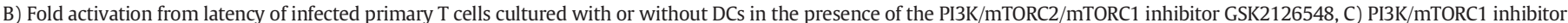

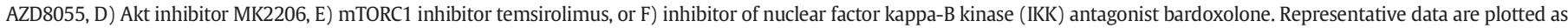
the average fold activation with standard error of the mean at the different indicated concentrations of inhibitor from three independent cultures. Drug toxicity is indicated with $§$. 


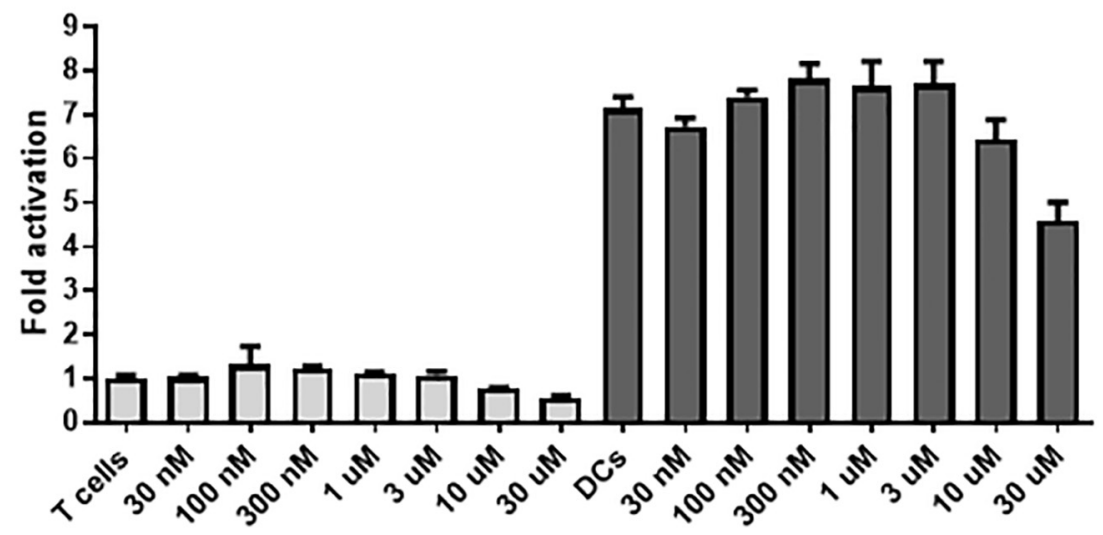

B

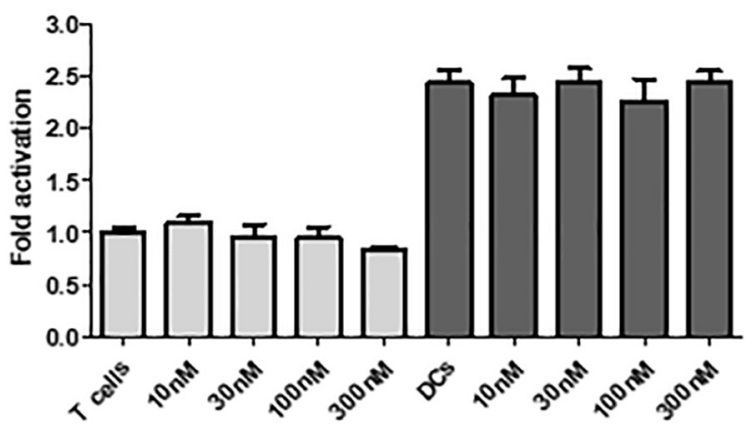

C

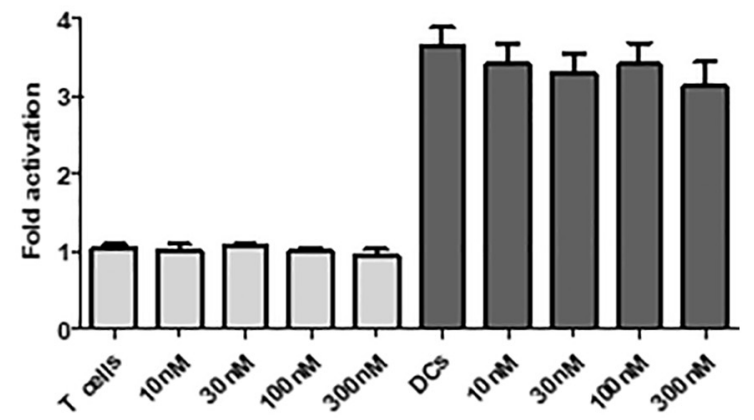

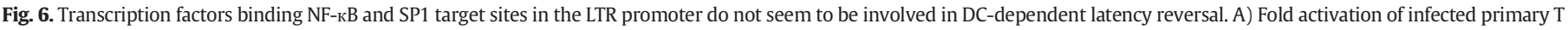

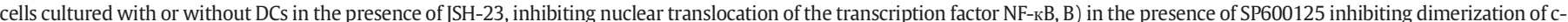

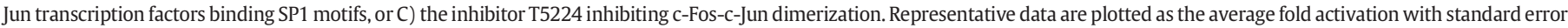

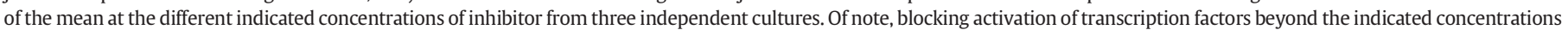
of JSH-23 and SP600125 was toxic for T cells regardless of whether they were co-cultured with DCs (results not shown).

\subsection{Analysis of DC-mediated signaling downstream of the Akt pathway}

To confirm involvement of the PI3K-Akt-mTOR pathway, we tested additional inhibitors that block specific steps of this pathway (Fig. 5A). The inhibitor GSK2126548 that blocks the activation of PI3K, mTORC1 and mTORC2, the mTOR-inhibitor AZD8055 that blocks activation of mTORC1 and mTORC2, and the Akt-inhibitor MK2206 all inhibited DCmediated HIV-purging in a dose-dependent manner (Fig. 5B-D). These inhibitors had no significant effect on HIV-1 production in T-cell only cultures, but a negative purging trend seemed to occur. The results again illustrate that an active mTOR pathway in activated T cells is involved in the induction of virus production [23]. We used the inhibitor temsirolimus to specifically inhibit mTORC1, which inhibited DCmediated reversion of latent HIV-1 by $70 \%$ at concentrations as low as $10 \mathrm{nM}$, without any cell toxicity (Fig. 5E). Inhibiting the IאB kinase (IKK) complex, another signaling branch downstream of Akt with bardoxolone also blocked HIV-1 reactivation, but only at high concentrations above $100 \mathrm{nM}$ (Fig. 5F). In summary, although the PLC, PKC, MEK/ERK and PI3K/Akt pathways are activated in PHA-activated T cells, a further stimulation of the PI3K/Akt pathway by DC contact purged latent HIV-1 beyond the level of TCR activation.

3.5. DC contact does not increase availability of nuclear NF-кB or cJun/cFos (hetero/homo) dimers

The I $\kappa \mathrm{K}$ pathway is involved in activation of the transcription factor NF-кB. To explore whether the purging effect mediated by DCs is dependent on increased transcription initiation, we blocked nuclear translocation of NF-кB with JSH-23 [24], which did not inhibit DCmediated reversal of latency up to $3 \mu \mathrm{M}$ (Fig. 6A). Higher concentrations of JSH-23 partially inhibited the DC purging effect, but these high concentrations also induced latency in the absence of DCs. This result illustrates that latency can be induced by blocking nuclear translocation of the NF- $\mathrm{KB}$, but the purging ability observed with DCs is not dependent on increased production or translocation of NF-кB. Blocking c-Jun (Fig. 6B) or C-Fos (Fig. 6C), transcription factors that bind to AP-1 and SP1 sites in the HIV-1 LTR promoter, also did not affect DC-mediated purging. Thus, the availability of transcription factors that are important for HIV-1 gene expression in activated effector T cells is sufficient and is not changed upon DC addition.

\subsection{DCs trigger (de)phosphorylation of proteins downstream of the Akt sig- naling pathway}

To explore which pathways become activated by DCs in effector T cells, we also studied the phosphorylation status of 43 proteins from different signaling cascades. Seven proteins that belong to the Akt signaling pathway became phosphorylated upon $2.5 \mathrm{~h}$ DC contact (p38alpha, JNK1/2/3, GSK-3AB, p53, CREB, c-Jun and WNK-1) (Fig. 7A and $C$ ). Surprisingly, two other proteins that are also associated with Akt signaling, p27 and p70SK6, became dephosphorylated. It could be that these kinases were dephosphorylated to prevent over-activation of the mTOR pathway via negative feedback loops. Apart from the over-all activation of the Akt pathway, we also observed STAT5/6 proteins being less frequently phosphorylated after DC contact. We then analysed the phosphorylation status after an extended (21h) DC 
A

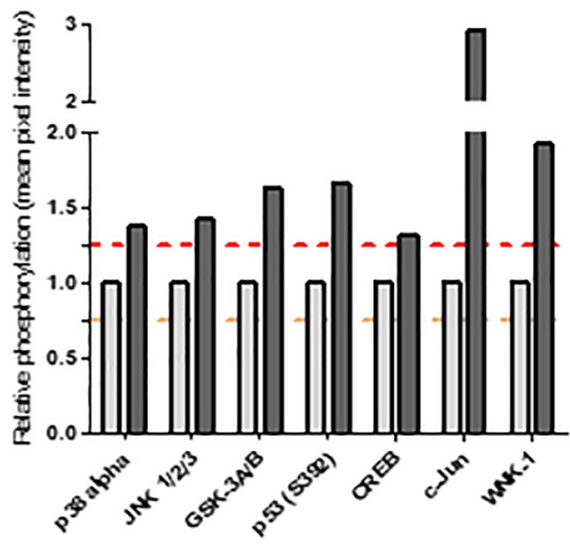

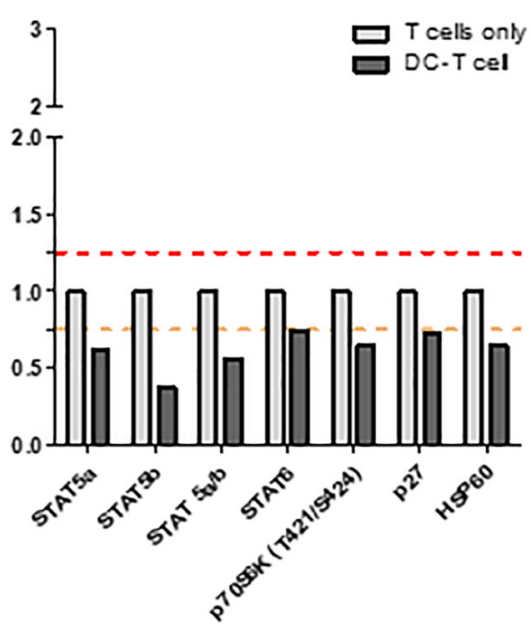

B

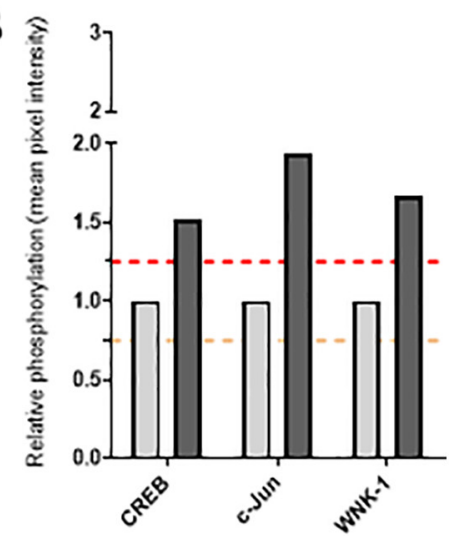

C

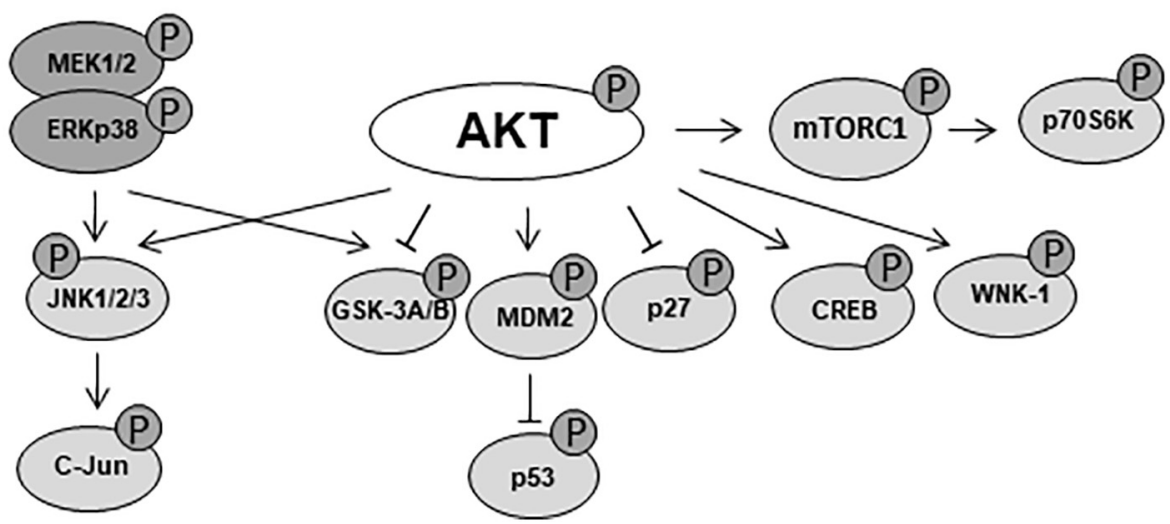

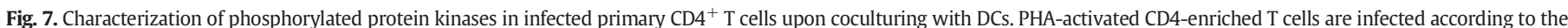

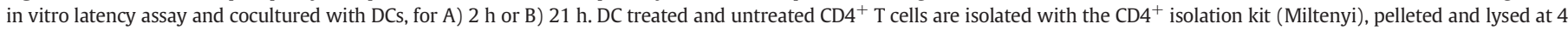

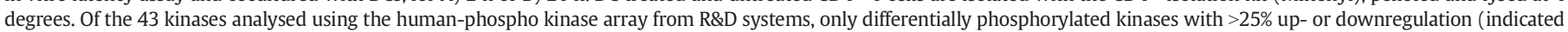

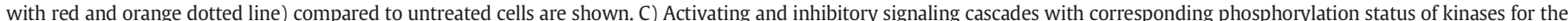

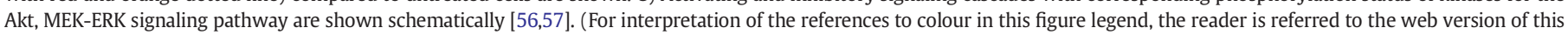
article.)

contact. Three proteins (CREB, WNK-1 and c-Jun) downstream the Akt pathway still showed an increased phosphorylation status (Fig. 7B). Thus, part of the PI3K-Akt-mTOR pathway in T cells remains active upon prolonged DC contact. Overall, these results provide evidence that DCs activate the PI3K-Akt-mTOR pathway in T cells, thus purging latent HIV-1 proviruses.

\subsection{DCs purge latent HIV-1 in TCR activated CD4 cells from aviremic patients}

Since DCs activate the PI3K-Akt-mTOR pathway and purge latent HIV-1 in activated T cells, we examined whether they can also purge latent HIV-1 beyond PHA-mediated activation in $\mathrm{CD}^{+}{ }^{+} \mathrm{T}$ cells from aviremic HIV-infected patients. CD4 ${ }^{+} \mathrm{T}$ cells were isolated from 9 aviremic ART-treated patients and stimulated with PHA or mocktreated in the absence or presence of heterologous DCs for $72 \mathrm{~h}$. Purging of HIV-1 latency was assessed by the detection of extracellular HIV-1 virion RNA released into the cell culture supernatant. In mock-stimulated $\mathrm{CD}^{+}{ }^{+} \mathrm{T}$ cells, HIV-1 RNA could be detected for 4 out of 9 patients (Fig. 8A). Treatment with PHA, however, also did not increase the detectability of HIV-1 RNA when compared to mock-stimulated CD4 ${ }^{+} \mathrm{T}$ cells and DC contact even slightly decreased the HIV+ scores, possibly due to consumption of free virus in the supernatant $[25,26]$. Importantly, a combined PHA + DC treatment made HIV-1 RNA detectable for 9 out of 9 patients, implying that non-responding patients cells (with PHA only), responded with virus production upon the DC stimulus (Fig. 8B). The analyses however showed that the mean amount of RNA produced upon combined treatment was not increased compared to a single PHA treatment, which again could be due to the capture of free virus by DCs.

Next, we tested reversion of latency from single cells with the quantitative virological outgrowth assay ( $\mathrm{qVOA}$ ) on $\mathrm{CD}^{+} \mathrm{T}$ cells from 10 aviremic patients. Due to a limited number of patient cells, obtained from $15 \mathrm{ml}$ of blood, we performed the qVOA with a cell density of 200.000 T cells per culture. With this number of T cells, if all cultures are positive, a maximal IUPM of 5 can be reached. An increased number of IUPM cells was observed for the PHA + DC treatment compared to a single PHA shock. For 4 patients replicating virus only grew out with the PHA + DC treatment. For two patients (10 and 12) an increased IUPM level was observed with the double treatment and no virus outgrowth occurred upon PHA or PHA + DC treatment for 3 patients (Fig. 8C and D). Therefore, we conclude that DCs can purge HIV-1 latency beyond levels achieved by PHA activation.

\section{Discussion}

The latent HIV-1 reservoir in patients under suppressive ART consists predominantly of long-lived resting memory $\mathrm{CD}^{+} \mathrm{T}$ cells [27]. A major proportion of the reservoir contains replication-incompetent proviral DNA that lacks gene fragments, is hypermutated, or is 
A
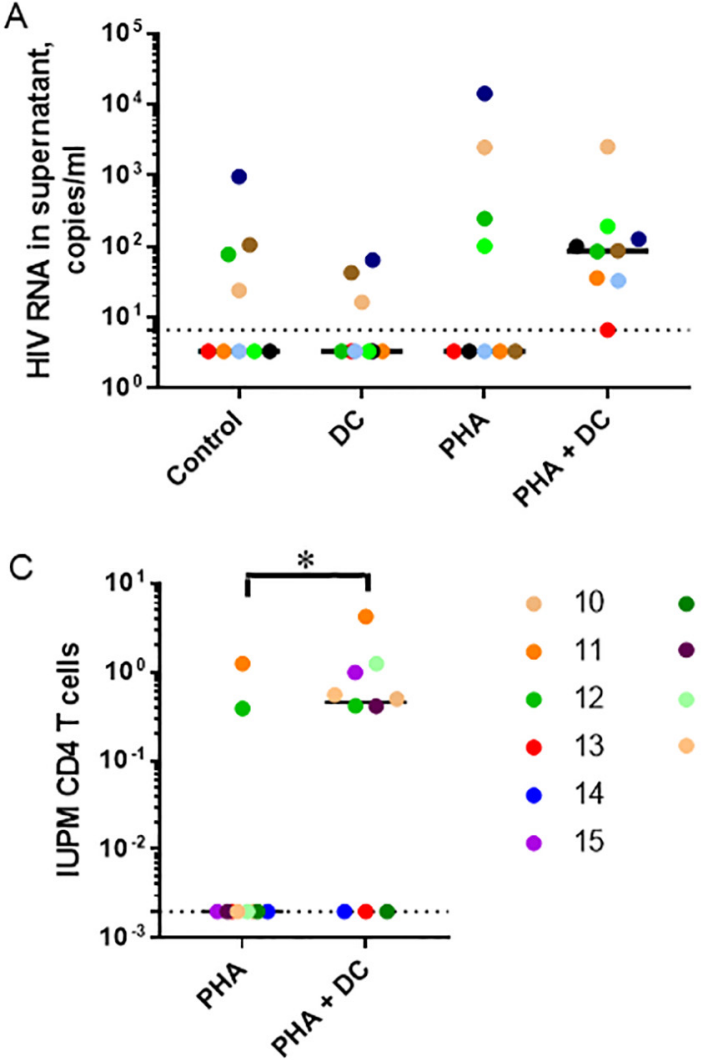

- 1

- 2

- 3

- 4

- 5

- 6

- 7

- 8

- 9
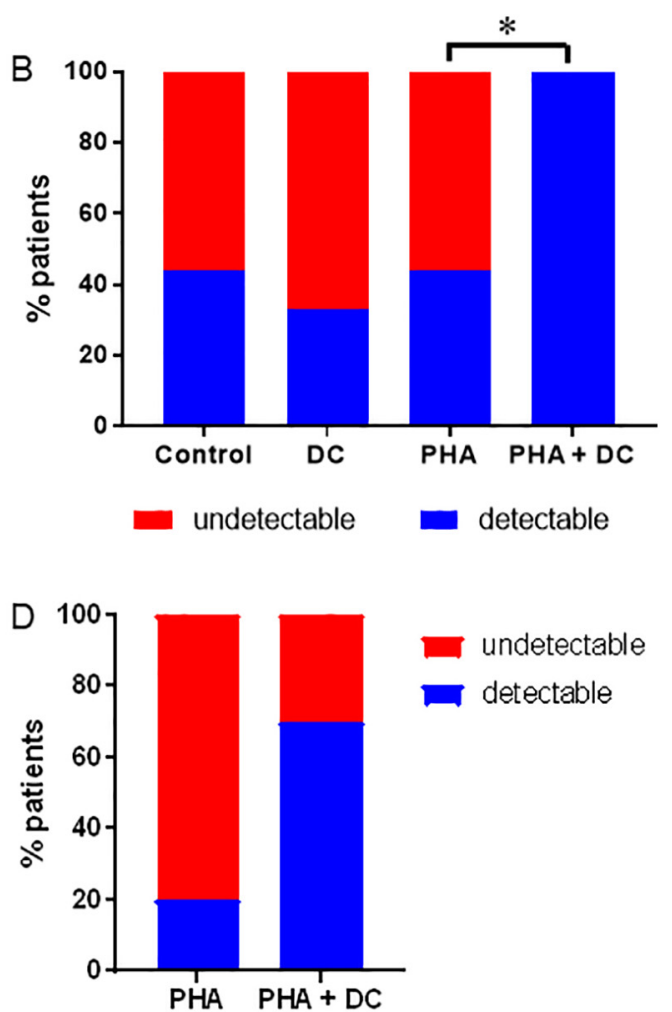

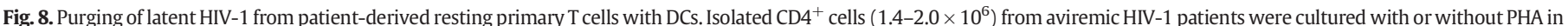

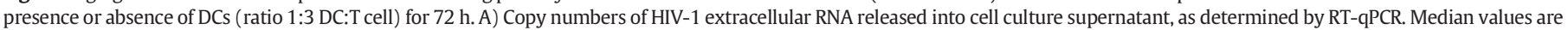

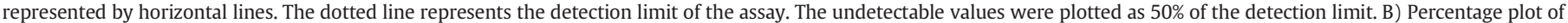

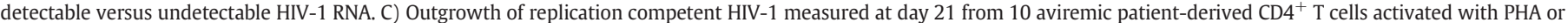

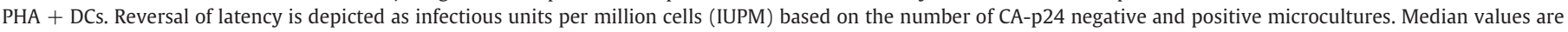
represented by horizontal lines. D) Percentage plot of detectable versus undetectable replication competent HIV- 1 after differential stimulation for these patient samples.

epigenetically silenced [28] [29]. However, based on sequencing, approximately 30 resting $T$ cells per million still contain infectious replication-competent HIV-1 genomes [12]. TCR activation that converts resting T cells into effector T cells can only purge HIV-1 in approximately 1 resting $\mathrm{T}$ cell per million [12,30]. Even though a full T-cell activation status is reached, sequential stimulation with a second TCRbased stimulus can increase the purging efficiency 2-3 fold [13], suggesting that latency persisted in most activated $\mathrm{T}$ cells. To study if more complete purging is feasible, we developed an HIV-1 latency model with (TCR pre-stimulated) primary effector T cells [5]. We provide evidence implicating DC contact in efficiently purging latent HIV in these T cells, something not achieved by a second round of T-cell activation or treatment with other LRAs (Fig. 2). Thus, the one-two punch consisting of TCR activation and subsequent stimulus with DCs can reach a significantly larger portion of the reservoir than other purging methods.

Using $\mathrm{CD}^{+}{ }^{+} \mathrm{T}$ cells isolated from ART-treated aviremic patients, we confirmed results obtained with our in vitro latency model by showing that ex vivo TCR-stimulation combined with DC contact induced the release of HIV-1 RNA into the supernatant in a significantly larger proportion of patients compared with TCR stimulation alone, which is indicative for purging of latent HIV-1 [31]. Although RNA could be detected for all patients with the double treatment, the levels of RNA released were not increased. This could be caused by efficient capture and degradation of free HIV-1 by DCs $[25,26]$, which will strongly limit the amount of HIV-1 RNA to be detected in supernatant. In agreement with this hypothesis, treatment of patient cells with DCs alone without PHA activation also decreased the amount of RNA released in supernatant compared to untreated cells. To understand why DCs increase the purging efficiency we dissected the molecular mechanisms induced in T cells pretreated with PHA. Our data illustrate that formation of tetraspanin-enriched microdomains (TEMs) between DCs and T cells is important for the purging ability of DCs (Fig. 3A) [20,32-34]. These TEMs recruit PI4K to the membrane to locally produce phosphoinositols, such as phosphatidylinositol-4,5 bisphosphate (PtdIns $(4,5) \mathrm{P}_{2}$ ), which activate RAS via Shc proteins [22,35]. GTPbound RAS can activate the MEK-ERK, PLC-PKC and the PI3K-AktmTOR pathway. The MEK-ERK and PLC-PKC pathways are strongly activated upon TCR stimulation, achieved with the first PHA stimulus, which promotes HIV-1 transcription by increasing the levels of activated transcription factors such as NF-кВ $[36,37]$. Restimulating the TCR with CD3/CD28 Abs or PHA again did not increase HIV-1 latency purging, indicating that both these pathways are still fully activated. Stimulation with DCs, however, purged latency efficiently. This was predominantly caused by activation of the PI3K-Akt-mTOR pathway. Activation of this pathway is associated with improved RNA elongation, ribosomal activity, protein synthesis and cell survival [38]. Thus, activation of the PI3K-Akt-mTOR probably overcomes post-transcriptional blocks to form infectious viral particles. Whether activation of this pathway is strictly regulated via RAS activation or via other DC-T cell mediated interactions needs to be explored in future research.

We hypothesize that phosphoinositols, especially the availability of PtdIns (4,5) $\mathrm{P}_{2}$, determines HIV-1 latency at various levels (Fig. 9). First, transcription factors such as NF-кB or c-Jun/c-Fos are required for HIV1 transcription initiation $[30,31,38]$. These factors are upregulated via TCR stimulation, where PtdIns $(4,5) \mathrm{P}_{2}$ is converted by PLC into $\mathrm{IP}_{3}$ and DIAG in the MEK-ERK and PLC-PKC pathway [39]. Second, PI3K-AktmTOR pathway activation is required to allow transcriptional 


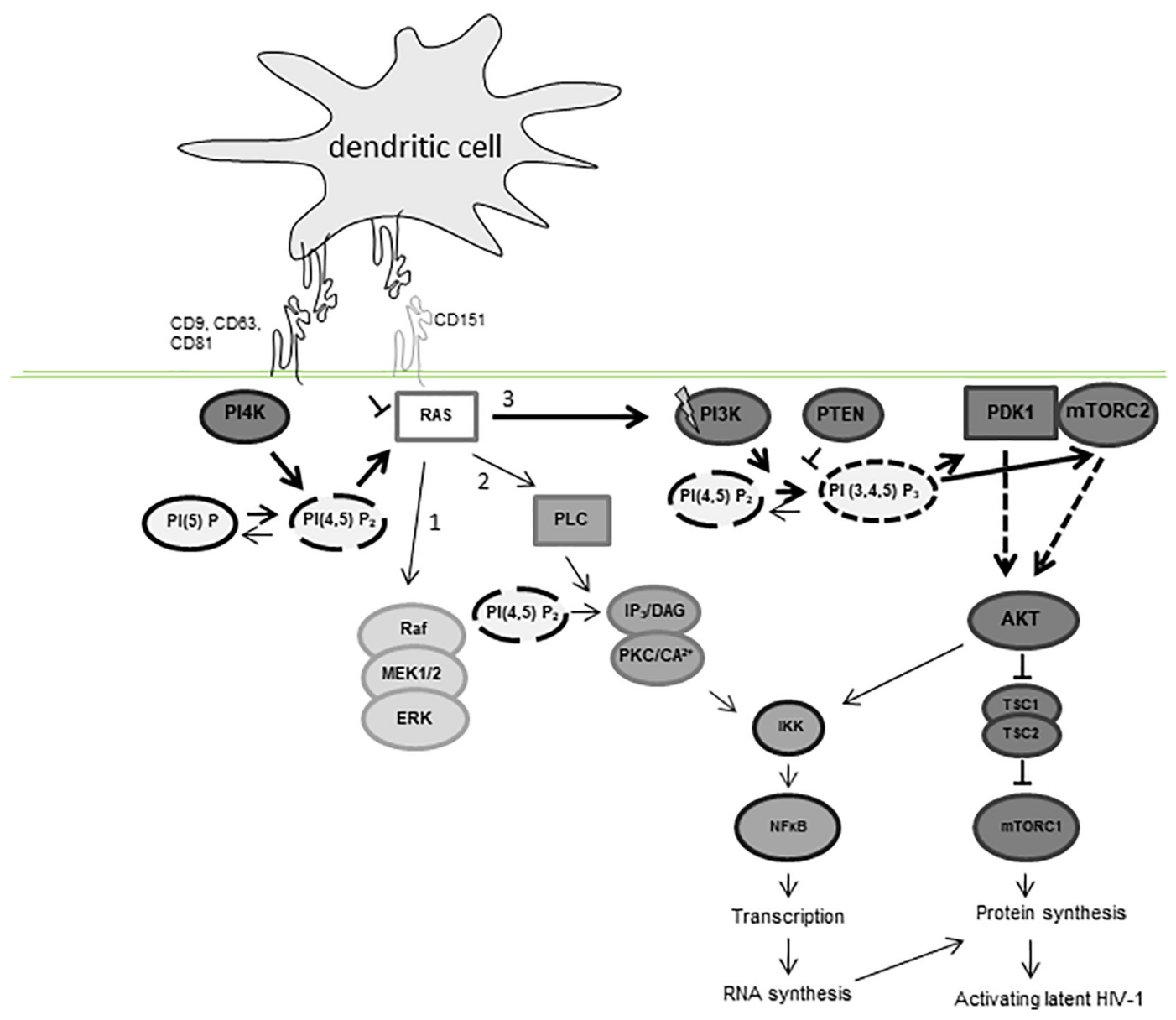

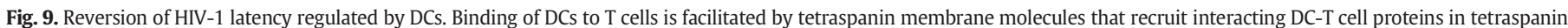

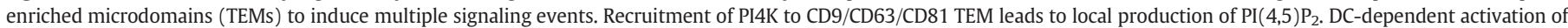

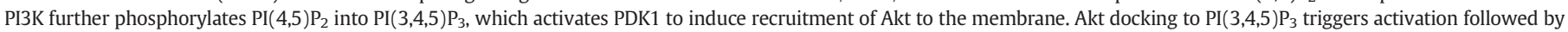

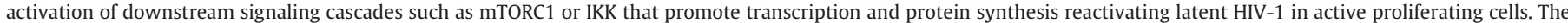
signaling cascade that is responsible for DC-mediated reversion of latent HIV-1 independent of T cell receptor activation is indicated with bold arrows.

elongation and protein synthesis. DCs can initiate this pathway by PtdIns (4,5) $\mathrm{P}_{2}$ production in TEMs via PI4K activation and subsequent phosphorylation into PtdIns(3,4,5) $\mathrm{P}_{3}$ by PI3K. Since the PI3K-AktmTOR and PLC-PKC pathway either phosphorylate or dephoshorylate PtdIns $(4,5) \mathrm{P}_{2}$, strong activation of either one of these pathways will directly inhibit the activation of the other pathway. Thus, a fine balance between these pathways should be pursued to purge latent HIV-1, or both pathways should be activated sequentially as achieved for instance with our "one-two punch" strategy, in which, after transcription initiation, RNA elongation and protein translation should follow.

In this light it is not surprising that TCR stimulation, which can trigger sub-optimally the PLC-PKC and PI3K-Akt-mTOR pathway, has some HIV-1 purging ability, leading to outgrowth of infectious particles. Solely activating the transcription initiation route using a PKC agonist, however, does not [30]. Interestingly, a recent study discovered the importance of the mTOR pathway in purging latent HIV-1 in resting cells [23]. Specifically blocking the mTOR pathway after TCR stimulation negated reversal of latency in patient cells, illustrating that TCRstimulation can sub-optimally activate this pathway. Our results extend those data by showing that activation of the PI3K-Akt-mTOR pathway by DCs, is stronger than stimulating the TCR in isolation, leading to increased purging efficiency.

Targeting multiple intermediates in the PI3K-Akt-mTOR pathway, e.g. using small molecule inhibitors, we dissected their contributions in reverting latency. For instance using GSK2126458, we found that it inhibited DC-specific activation of the PI3K-AKt-mTOR pathway better than the mTORC1 inhibitor temsirolimus. This is in agreement with a study from Martin et al., who reported that the mTORC1 inhibitor rapamycin $[40,41]$ did not block purging of latent HIV-1, but could reduce the toxic side effect of CD3/CD28 T cell activation without affecting CTL-mediated killing [42]. The use of small molecule inhibitors can have off-targets effects as well as general toxicities, which can distort results. In as far as possible our controls excluded these as a source of error. Our findings regarding the activation of the PI3K-Akt-mTOR pathway upon DC contact were futher corroborated by phosphate modification readouts. This again argues against aspecific effects of the small molecule inhibitors.

DC contact may influence HIV-1 reactivation in T cells by additional means. Ren et al. showed that mature DCs are capable of releasing TNF $\alpha$ upon contact with infected Jurkat $\mathrm{T}$ cells, leading to reversion of latency in this cell line [43].

Since DCs strongly revert HIV-1 latency, it would be an option to use DCs as a natural cell source to revert HIV-1 latency in HIV-infected patients. We previously observed that primary DCs homing to different lymphoid organs have substantially different latency-purging capacities. Monocyte-derived DCs cultured under conditions towards a gut DC phenotype efficiently purged latent HIV-1, whereas no, or only modest, reversal of latency was achieved with DCs representing the subtype homing to the genital tract. Myeloid DCs that have been matured with different toll-like receptor agonists, representing lymph node derived DCs, efficiently purge HIV-1 from latency [16]. The fact that monocytederived DCs can purge HIV-1 from patient-derived latently infected cells suggests that DCs might control the size of the viral reservoir in patients in particular tissues. This could happen especially when T cells are 
activated due to secondary infection, or in the acute phase of disease when T cells are activated to fight the HIV-1 infection [5]. DC-mediated HIV-1 reversion however, is not to be expected in peripheral blood [16], as the frequency of myeloid DCs is 7000 per million CD4 T cells in healthy donors, with even lower numbers in HIV-1 infected individuals ( 2300 per million) [44]. But, DC:T contact might be more efficient in tissues, which could result in the observed low levels of ongoing virus production, even in the presence of therapy $[45,46]$.

Interestingly, Gramatica and colleagues already raised the possibility that latency reversal might be more effective in lymphoid tissues where contact of T cells with DCs is more prominent than in blood [47]. The lack of efficacy of clinical trials using LRAs aimed at decreasing the HIV-1 reservoir size might therefore be caused by the fact that the reservoir was analysed only in the peripheral blood and not in tissues, where preferential DC-mediated purging could occur [48-52]. One approach to use DCs to increase the LRA purging efficiency in patients might be the combination of an LRA with specific TLR agonists that will direct DCs to tissues, where latent reservoirs are maintained. The use of DCs as a natural mechanism to revert HIV-1 latency has caveats and limitations, due to difficulties inherent in specific targeting of this interaction. However, if feasible this approach will have limited side effects [53] compared to using T cell receptor agonists [54].

Our results could have important implications. Firstly, the potent capacity of DCs to reactivate HIV-1 proviruses which were not purged despite PHA stimulation could be used to design a more sensitive culture-based assay to measure the replication-competent reservoir, for instance by adapting the promising TZM-bl based assay [55]. Secondly, the role of DCs in HIV-1 persistence highlights the need to look at tissue reservoirs when possible, since cell-to-cell contact appears to be a major factor controlling HIV-1 latency. Finally, our results further support the importance of the PI3K-Akt-mTOR pathway in HIV-1 latency. These novel insights could be used to develop more efficient LRA strategies in the quest to get rid of the latent HIV-1 reservoir.

\section{Acknowledgements}

We would like to thank George Leslie and Jim A. Hoxie for providing us with the SupT1 CCR5 T cell line [15]. Thijs van Montfort, Renée van der Sluis, Alexander O. Pasternak, Ben Berkhout and Rienk Jeeninga were financially supported by the Dutch Aidsfonds without other involvements (Project numbers 2007028, 2008014, 2011020, 2012025, 2013021 and P-22602; http://www.aidsfonds.nl/about/organisation). The corresponding author confirms that he had full access to all the data in the study and had final responsibility for the decision to submit for publication.

\section{Declaration of interest}

The authors declare no competing interests.

\section{Author contributions}

TvM, wrote the original manuscript draft; TvM, GJD, RvdS, MV, DB, $\mathrm{KG}, \mathrm{AOP}$ and BvdP carried out the investigation; MB, SJ took care of the project administration; GP, EMW, MH and JP provided resources; RJ, GD, AOP, AAMT, DS and BB helped with writing, reviewing and editing.

\section{References}

[1] Bruner KM, Murray AJ, Pollack RA, et al. Defective proviruses rapidly accumulate during acute HIV-1 infection. Nat Med 2016:22. https://doi.org/10.1038/nm.4156.

[2] Perelson AS, Neumann AU, Markowitz M, Leonard JM, Ho DD. HIV-1 dynamics in vivo: virion clearance rate, infected cell life-span, and viral generation time. Science 1996;271:1582-6 (80-)

[3] Wei X, Ghosh SK, Taylor ME, et al. Viral dynamics in human immunodeficiency virus type 1 infection. Nature 1995;373:117-22.
[4] Chavez L, Calvanese V, Verdin E. HIV latency is established directly and early in both resting and activated primary CD4 T cells. PLoS Pathog 2015;11:1-21.

[5] van der Sluis RM, van Montfort T, Pollakis G, et al. Dendritic cell-induced activation of Latent HIV-1 provirus in actively proliferating primary T lymphocytes. PLoS Pathog 2013:9:e1003259.

[6] Darcis G, Van Driessche B, Bouchat S, Kirchhoff F, Van Lint C. Molecular control of HIV and SIV latency. Current topics in Microbiology and Immunology. Berlin, Heidelberg: Springer Berlin Heidelberg; 2017. p. 1-22.

[7] Yukl SA, Kaiser P, Kim P, et al. HIV latency in isolated patient CD4+ T cells may be due to blocks in HIV transcriptional elongation, completion, and splicing. Sci Transl Med 2018;10http://stm.sciencemag.org/content/10/430/eaap9927.abstract.

[8] Huang J, Wang F, Argyris E, et al. Cellular microRNAs contribute to HIV-1 latency in resting primary CD4+T lymphocytes. Nat Med 2007;13:1241-7.

[9] Zolotukhin AS, Michalowski D, Bear J, et al. PSF acts through the human immunodeficiency virus type $1 \mathrm{mRNA}$ instability elements to regulate virus expression. Mol Cell Biol 2003;23:6618-30.

[10] Kula A, Gharu L, Marcello A. HIV-1 pre-mRNA commitment to Rev mediated export through PSF and Matrin 3. Virology 2013;435:329-40.

[11] Yedavalli VSRK, Jeang KT. Matrin 3 is a co-factor for HIV-1 Rev in regulating posttranscriptional viral gene expression. Retrovirology 2011;8:1-10.

[12] Ho Y-C, Laird GM, Siliciano RF. Measuring reversal of HIV-1 latency ex vivo using cells from infected individuals. Proc Natl Acad Sci 2014;111:6860-1.

[13] Hosmane NN, Kwon KJ, Bruner KM, et al. Proliferation of latently infected CD4+ T cells carrying replication-competent HIV-1: potential role in latent reservoir dynamics. J Exp Med 2017;214:959-72.

[14] van Montfort T, Thomas AAM, Pollakis G, Paxton WA. Dendritic cells preferentially transfer CXCR4-using human immunodeficiency virus type 1 variants to CD4+ T lymphocytes in trans. J Virol 2008;82:7886-96.

[15] Del Prete GQ Haggarty B, Leslie GJ, et al. Derivation and characterization of a simian immunodeficiency virus SIVmac239 variant with tropism for CXCR4. J Virol 2009; 83:9911-22

[16] van der Sluis RM, van Capel TMM, Speijer D, et al. Dendritic cell type-specific HIV-1 activation in effector T cells. AIDS 2015;29:1003-14.

[17] Boom R, Sol C, Salimans M, Jansen C, Wertheim-van Dillen P, van der Noordaa J. Rapid and simple method for purification of nucleic acids. J Clin Microbiol 1990; 28:495-503.

[18] Malnati MS, Scarlatti G, Gatto F, et al. A universal real-time PCR assay for the quantification of group-M HIV-1 proviral load. Nat Protoc 2008;3:1240.

[19] Fun A, Mok HP, Wills MR, Lever AM. A highly reproducible quantitative viral outgrowth assay for the measurement of the replication-competent latent HIV-1 reservoir. Sci Rep 2017;7:1-10.

[20] Rocha-Perugini V, Sánchez-Madrid F, Del Hoyo GM. Function and dynamics of tetraspanins during antigen recognition and immunological synapse formation. Front Immunol 2016;6:1-12.

[21] Rocha-Perugini V, González-Granado JM, Tejera E, López-Martín S, Yañez-Mó M, Sánchez-Madrid F. Tetraspanins CD9 and CD151 at the immune synapse support T-cell integrin signaling. Eur J Immunol 2014;44:1967-75.

[22] Hemler ME. Tetraspanin functions and associated microdomains. Nat Rev Mol Cell Biol 2005;6:801-11.

[23] Besnard E, Hakre S, Kampmann M, et al. The mTOR complex controls HIV latency. Cell Host Microbe 2016;20:785-97.

[24] Shin HM, Kim MH, Kim BH, et al. Inhibitory action of novel aromatic diamine compound on lipopolysaccharide-induced nuclear translocation of NF- $\kappa \mathrm{B}$ without affecting IKB degradation. FEBS Lett 2004:571:50-4.

[25] van Montfort T, Eggink D, Boot M, et al. HIV-1 N-glycan composition governs a balance between dendritic cell-mediated viral transmission and antigen presentation. J Immunol 2011:187:4676-85.

[26] van Montfort T, Thomas AAM, Krawczyk PM, Berkhout B, Sanders RW, Paxton WA. Reactivation of neutralized HIV-1 by dendritic cells is dependent on the epitope bound by the antibody. J Immunol 2015;195:3759-68.

[27] Zhang L, Ramratnam B, Tenner-Racz K, et al. Quantifying residual HIV-1 replication in patients receiving combination antiretroviral therapy. N Engl J Med 1999;340: 1605-13.

[28] Kieffer TL, Kwon P, Nettles RE, Han Y, Ray SC, Siliciano RF. G $\rightarrow$ A hypermutation in protease and reverse transcriptase regions of human immunodeficiency virus type 1 residing in resting CD4 $+\mathrm{T}$ cells in vivo G3A hypermutation in protease and reverse transcriptase regions of human immunodeficiency virus type 1 resid. J Virol 2005; 79:1975-80

[29] Sanchez G, Xu X, Chermann JC, Hirsch I. Accumulation of defective viral genomes in peripheral blood mononuclear cells of human immunodeficiency virus type 1infected individuals. J Virol 1997;71:2233-40.

[30] Bullen CK, Laird GM, Durand CM, Siliciano JD, Siliciano RF. New ex vivo approaches distinguish effective and ineffective single agents for reversing HIV-1 latency in vivo. Nat Med 2014;20:425-9.

[31] Laird GM, Bullen CK, Rosenbloom DIS, et al. Ex Vivo Analysis Identifies Effective HIV1 Latency - Reversing Drug Combinations, 125; 2015; 1-12.

[32] Berditchevski F, Tolias KF, Wong K, Carpenter CL, Hemler ME. A novel link between integrins, transmembrane-4 superfamily proteins (CD63 and CD81), and phosphatidylinositol 4-kinase. J Biol Chem 1997;6:2595-8.

[33] Mittelbrunn M, Yáñez-Mó M, Sancho D, Ursa A, Sánchez-Madrid F. Cutting edge: dynamic redistribution of tetraspanin CD81 at the central zone of the immune synapse in both T lymphocytes and APC. J Immunol 2002;169:6691-5.

[34] Lin W, Fan Z. Immunological synapse molecules. J Immuno Biol 2016;1:1-6.

[35] Pawson T, Scott JD. Signaling through scaffold, anchoring, and adaptor proteins. Science 1997;278:2075-80 (80- ). 
[36] Li YQ Hii CST, Der CJ, Ferrante A. Direct evidence that ERK regulates the production/ secretion of interleukin-2 in PHA/PMA-stimulated T lymphocytes. Immunology 1999;96:524-8.

[37] Coudronniere N, Villalba M, Englund N, Altman A. NF-kB activation induced by T cell receptor/CD28 costimulation is mediated by protein kinase C $-\theta$. Proc Natl Acad Sci 2000;97:3394-9.

[38] Darcis G, Kula A, Bouchat S, et al. An in-depth comparison of latency-reversing agent combinations in various in vitro and ex vivo HIV-1 latency models identified bryostatin-1+JQ1 and ingenol-B+JQ1 to potently reactivate viral gene expression. PLoS Pathog 2015;11:e1005063.

[39] Mendoza MC, Er EE, Blenis J. The Ras-ERK and PI3K-mTOR pathways: cross-talk and compensation. Trends Biochem Sci 2011;36:320-8.

[40] Calne RY, Lim S, Samaan A, et al. Rapamycin for Immunosuppression in Organ Allografting. Lancet 1989;334:227.

[41] Ernst E, Neumann CH, Laporte JR, Jarnet J, Woo J. Immunosuppressive properties of FK-506 and rapamycin. Lancet 1989;2:443-4.

[42] Martin AR, Pollack RA, Capoferri A, Ambinder RF, Durand CM, Siliciano RF. Rapamycin-mediated mTOR inhibition uncouples HIV-1 latency reversal from cytokine-associated toxicity. J Clin Invest 2017;127:651-6.

[43] Ren X-X, Ma L, Sun W-W, et al. Dendritic cells maturated by co-culturing with HIV-1 latently infected Jurkat T cells or stimulating with AIDS-associated pathogens secrete TNF-alpha to reactivate HIV-1 from latency. Virulence 2017;1(12).

[44] Donaghy H, Pozniak A, Gazzard B, et al. Patients With HIV-1 Infection Correlates With HIV-1 RNA Virus Load Brief Report Loss of Blood CD11c 2 Myeloid and CD11c X Plasmacytoid Dendritic Cells in Patients With HIV-1 Infection Correlates With HIV-1 RNA Virus Load, 98; 2012; 2574-6.

[45] Lorenzo-Redondo R, Fryer HR, Bedford T, et al. Persistent HIV-1 replication maintains the tissue reservoir during therapy. Nature 2016;530:51-6.

[46] Pasternak AO, De Bruin M, Jurriaans S, et al. Modest nonadherence to antiretroviral therapy promotes residual HIV-1 replication in the absence of virological rebound in plasma. J Infect Dis 2012;206:1443-52.
[47] Gramatica A, Greene WC, Montano M. Lymphoid tissue and blood CD4 T cells respond differently to latency-reversing agents: are we testing the right cells? J Virus Erad 2015;2015.

[48] Archin NM, Liberty AL, Kashuba AD, et al. Administration of vorinostat disrupts HIV1 latency in patients on antiretroviral therapy. Nature 2012;487:482-5.

[49] Søgaard OS, Graversen ME, Leth S, et al. The depsipeptide romidepsin reverses HIV-1 latency in vivo. PLoS Pathog 2015;11:1-22.

[50] Rasmussen TA, Tolstrup M, Brinkmann CR, et al. Panobinostat, a histone deacetylase inhibitor, for latent-virus reactivation in HIV-infected patients on suppressive antiretroviral therapy: a phase 1/2, single group, clinical trial. Lancet HIV 2018;1: e13-21.

[51] Gutiérrez C, Serrano-Villar S, Madrid-Elena N, et al. Bryostatin-1 for latent virus reactivation in HIV-infected patients on antiretroviral therapy. AIDS 2016;30: 1385-92.

[52] Spivak AM, Andrade A, Eisele E, et al. A pilot study assessing the safety and latencyreversing activity of disulfiram in HIV-1-infected adults on antiretroviral therapy. Clin Infect Dis 2014;58:883-90.

[53] Palucka K, Banchereau J. Dendritic-cell-based therapeutic cancer vaccines. Immunity 2013;39:38-48.

[54] Prins JM, Jurriaans S, van Praag RM, et al. Immuno-activation with anti-CD3 and recombinant human IL-2 in HIV-1-infected patients on potent antiretroviral therapy. AIDS 1999;13:2405-10.

[55] Sanyal A, Mailliard RB, Rinaldo CR, et al. Novel assay reveals a large, inducible, replication-competent HIV-1 reservoir in resting CD4+T cells. Nat Med 2017;23: $885-9$.

[56] Bunney TD, Katan M. Phosphoinositide signalling in cancer: beyond PI3K and PTEN Nat Rev Cancer 2010;10:342-52.

[57] Downward J. Targeting RAS signalling pathways in cancer therapy. Nat Rev Cancer 2003;3:11-22. 